\title{
APLIKASI SNACK VIDEO DALAM PERSPEKTIF HUKUM ISLAM
}

\author{
Raudatunnisa ${ }^{1}$, Galuh Nashrulloh Kartika $\mathrm{MR}^{2}$, Umi Hani ${ }^{3}$ \\ UNISKA Muhammad Arsyad Al Banjari, Banjarmasin, Indonesia ${ }^{1,2,3}$ \\ Email : raudatunnisa027@gmail.com, galuh.nashrulloh@uniska-bjm.ac.id, \\ umihani.uniska@gmail.com
}

\begin{abstract}
One of the most popular applications recently is Snack Video, an application that offers users income by watching videos, checking in, and inviting new friends to use the application. In Islamic law, muamalah does not only follow the pillars and conditions of the contract but the principles of muamalah must also be considered so that the implementation of the contract is valid and in accordance with sharia. If it is categorized in a muamalah contract, getting money from the Snack Video application is like a competition in Islam called ju'alah, in its use this application has not been legally confirmed in accordance with the ju'alah contract. This research will reveal how to earn money through the Snack Video application and how to analyze contracts and muamalah principles in the Snack Video application. The field research conducted online with Snack Video users was selected using a case study approach through sampling methods from various places in the Barito Kuala district. Data was collected by using interviews, observation, and documentation techniques. The results of this study conclude: first, to earn money from the Snack Video application, users are directed to carry out missions to watch videos, check in, and invite friends. From successful missions, the user will be rewarded with coins that can be exchanged for money. Second, analysis of the contract and muamalah principles in the Snack Video application, the mission in the Snack Video application such as competitions in the muamalah contract is called ju'alah which may be used as a means of making money, provided that the mission carried out does not conflict with Islamic law, the principles muamalah and does not cause harm or immorality. The income obtained from watching the Snack Video application becomes makruh and can even become haram if accompanied by activities that can reduce the value of maqashid sharia on the daruriyyat element, namely hifdz al-mal, protecting property from vanity elements Giving appreciation to content video creators is the same as grants.
\end{abstract}

Keywords: Application Snack Video, Islamic Law

Kecanggihan teknologi di masa sekarang menawarkan berbagai macam cara agar seseorang dengan mudah dapat menghasilkan uang walau tidak harus bekerja keras, seperti hanya melakukan aktivitas menonton iklan, film, maupun video pada aplikasi khusus secara online, seseorang dengan mudah dapat menerima uang dari aktivitas tersebut.

Salah satu aplikasi menonton video yang ramai digunakan sekarang ini oleh sebagian masyarakat Indonesia adalah aplikasi Snack video yaitu aplikasi yang menawarkan pendapatan bagi siapa saja dengan hanya menonton video konten dari kiriman pengguna aplikasi tersebut, melakukan misi check-in harian juga dengan cara mengajak teman untuk ikut menggunakannya. Aplikasi Snack Video merupakan aplikasi milik perusahaan bernama Kuaishou Technology asal 
Beijing, China yang didukung oleh perusahaan Tencent Holding sebagai investor. Sementara di Google Play Store, aplikasi ini telah diunduh sebanyak lebih dari 100 juta kali sejak pertama diluncurkan pada tanggal 7 Agustus 2019, konten Snack Video memberikan batas durasi selama 57 detik saja (Novika, Nonton Video Bisa Dapat Duit, Aman Nggak Ya? 2021).

Kompas.com nenyebutkan bahwa pada bulan Februari 2021 aplikasi Snack Video termasuk dalam daftar aplikasi ilegal oleh Otoritas Jasa Keuangan (OJK) (Dewi, 2021). Diblokirnya Snack Video oleh Kementerian Komunikasi dan Informatika Indonesia dan berstatus ilegal oleh OJK karena diduga aplikasi tersebut berjenis Money Game yaitu kegiatan mengumpulkan dana anggota atau penggandaan uang dengan cara memberikan bonus dari hasil pencarian anggota baru yang mendaftar atau ikut bergabung bukan dari hasil penjualan produk (Harizan 2017). Pemblokiran aplikasi Snack Video di India diduga karena bocornya data pribadi hingga merugikan banyak pihak (Gautama 2021).

Sejak tanggal 23 Maret 2021 SWI (Satgas Waspada Investasi) menetapkan bahwa Snack Video dinyatakan legal karena telah memenuhi persyaratan perizinan baik (Perizinan Sistem Elektronik) dan (Perdagangan Melalui Sistem Elektronik) (Admin, GarutSelatan.Info, https://www.garutselatan.info/2021/03/kabar-terbaruswi-nyatakan-snack-video-legal.htm 2021).

Dilegalkannya Snack Video tidak menjamin akad yang mereka gunakan dalam kegiatan tersebut sudah sesuai syariat Islam. Namun, apabila dikategorikan dalam akad ekonomi Islam kegiatan mendapat uang dengan menonton video terlihat seperti perlombaan (sayembara) dalam Islam disebut dengan akad Ju'alah (MUI 2017). Penelitian ini mengungkapkan bagaimana cara mendapat uang dari aplikasi Snack Video dan menjelaskan analisis Hukum Islam terhadap akad dan asas-asas muamalah pada aplikasi Snack Video. Penelitian ini diharapkan memberikan kejelasan hukum terhadap muamalah yang berlaku termasuk content baru seperti Snack Video

Berdasarkan penelusuran penulis, sejauh ini belum penulis temukan penelitian yang sama. Skripsi yang ditulis oleh Ika Lestari tahun 2020 dari IAIN Purwokerto yang berjudul "Pandangan Peserta Bahtsul Masail Munas Alim 
Ulama NU di Banjarpatroman Tahun 2019 Tentang Keharaman Multi Level Marketing (MLM)". Penelitian ini berbeda penelitian penulis, meskipun pada dasarnya di dalam aplikasi Snack Video diperkirakan terdapat bisnis MLM dari event mengundang teman. Penulis lebih membahas tentang analisis akad dan asasasas muamalah pada aplikasi Snack Video.

Penelitian lain yang ditulis oleh Yoni Arief Perdana, yang berjudul “Tinjauan Hukum Islam Terhadap Praktik Paid To Click (PTC) (Studi Kasus di www.donkeymails.com)". Meskipun ada kesamaan dalam pemberian hadiah bagi pengguna, akan tetapi pada aplikasi Snack Video hadiah diberikan jika pengguna menonton video pada aplikasi tersebut, bukan kepada pengguna internet yang membuka iklan. Sehingga dapat dikatakan bahwa penelitian yang membahas tentang aplikasi penghasil uang seperti Snack Video belum pernah diteliti sebelumnya.

\section{METODE}

Metode penelitian yang digunakan adalah metode penelitian naturalistik (Sugiono 2019) dengan teknik pendekatan studi kasus. Pada penelitian lapangan (field research) atau studi kasus ini penulis menggunakan analisis akad ju'alah dan asas-asas muamalah pada aplikasi Snack Video.

Dalam menentukan subjek penelitian (Luthfiyah 2017) penulis menggunakan teknik probability sampling (simple random sampling) dari berbagai tempat di kabupaten Barito Kuala (Sugiyono 2019), Subjek penelitian dalam penelitian ini adalah para pengguna aplikasi Snack Video. Sedangkan objek penelitian (Sugiyono 2019) pada penelitian ini adalah analisis akad ju'alah dan asas-asas muamalah pada aplikasi Snack Video. Penelitian ini berlangsung selama 2 bulan yaitu dari tanggal 15 April 2021 sampai dengan 15 Juni 2021 dengan data utama dari para pengguna aplikasi Snack Video dan data tambahan tertulis yang diambil dari buku, jurnal, dokumen, berita, penelitian sebelumnya dan sumber data yang terkait dengan penelitian ini.

Teknik pengumpulan data (Barlian 2016) yang digunakan adalah Wawancara (Interview) (Ismail Suardi Wekke 2019), observasi dan dokumentasi 
(Sugiono 2019). Studi dokumen melengkapi teknik pengumpulan data wawancara dan observasi. Peneliti menggunakan analisis data model Miles dan Huberman (Sugiono 2019) yaitu, reduksi data (data reduction), penyajian data dan penarikan kesimpulan (Hardani 2020). Trianggulasi pada penelitian ini mencakup Trianggulasi Sumber, Trianggulasi Teknik dan Trianggulasi Waktu.

\section{HASIL}

Mendapatkan uang dari aplikasi Snack Video dapat dilakukan pengguna dengan mengunduh aplikasi Snack Video terlebih dahulu melalui Google Play Store. Setelah itu, pengguna dapat melakukan pendaftaran agar dapat bergabung sebagai pengguna aplikasi Snack Video. Saat semua persyaratan telah dilakukan, agar aplikasi tersebut dapat menghasilkan uang, pengguna akan diarahkan untuk menjalankan misi-misi seperti misi menonton video, check-in, dan mengundang teman. Dari misi-misi yang berhasil dilakukan tersebut pengguna akan diberikan imbalan berupa koin yang dapat ditukar menjadi uang. Uang yang telah terkumpul dapat dicairkan melalui aplikasi e-money (OVO, Dana dan GoPay) atau juga bisa ditukar menjadi voucher pulsa atau kuota internet yang dapat ditukarkan pada aplikasi Shopee.

Hukum Islam menelisik berdasarkan analisis akad dan asas-asas muamalah pada aplikasi Snack Video, kegiatan yang ada pada aplikasi Snack Video sama halnya dengan sayembara atau dalam fiqh muamalah disebut sebagai akad ju'alah yang boleh dijadikan sebagai sarana penghasil uang dengan menjalankan misi-misi yang diarahkan dengan catatan selama misi-misi yang diarahkan oleh pihak Snack Video tidak bertentangan dengan hukum Islam, maqashid Syariah, dan tidak membawa kemudharatan serta kemaksiatan. Melakukan pembelian produk pada aplikasi Snack Video sebagai tujuan donasi atau apresiasi kepada pembuat video konten juga diperbolehkan karena dalam fiqh muamalah pemberian seperti ini sama dengan akad hibah, hal ini diperbolehkan selama video yang mereka tampilkan tidak mengarah pada kemaksiatan dan kemudharatan.

\section{PEMBAHASAN}




\section{Pengertian Hukum Islam}

Hukum dalam bahasa Perancis "Droit", Belanda "Recht", Inggris "Law" yang artinya aturan. Hukum adalah suatu nilai, norma, dan kaidah dalam menjawab dan mengatur masalah masyarakat sehingga tercapai keadilan (Nurhayati 2020). Hukum merupakan peraturan atau adat yang secara sah bersifat mengikat yang diresmikan oleh pemerintah yang berfungsi untuk mengatur kehidupan bermasyarakat (Kementerian Pendidikan dan Kebudayaan Republik Indonesia 2021). Hukum merupakan peraturan dari kebiasaan dan sanksi yang dibuat untuk mengatur kebiasaan tingkah laku manusia, menjaga keadilan, ketertiban dan mencegah kekacauan (Suryaningsih 2018). Jika disederhakan, hukum adalah kumpulan aturan yang berfungsi untuk mengatur dan menjawab permasalahan masyarakat agar terciptanya kehidupan yang berkeadilan dan harmonis.

Hukum Islam berasal dari dua kata, yakni Hukum dan Islam. Kata Hukum berasal dari bahasa Arab Al-Hukm yang artinya 'memimpin', 'memerintah', 'memutuskan','mengadili', atau 'memutuskan' (Marzuki 2017). Islam berasal dari kata salima-yaslamu-salaman-wa salamatan yang berarti selamat. (Rohidin 2016). Islam diartikan sebagai agama Allah SWT yang diturunkan kepada Rasulullah SAW untuk disampaikan kepada seluruh umat manusia agar mendapat keselamatan di dunia dan di akhirat (Marzuki 2017). Sehingga Hukum Islam dapat diartikan sebagai seperangkat aturan-aturan atau norma yang bersumber dari Allah SWT untuk mengatur tingkah laku umat Islam dalam bermasyarakat.

\section{Pengertian Fiqh Muamalah}

Fiqh muamalah terdiri atas dua kata yakni Fiqh dan Muamalah. Secara bahasa fiqh berarti 'paham', 'mengetahui', 'melaksanakan.' Sedangkan kata Muamalah berasal dari bahasa Arab aamala-yuamilu-muamalati yang berarti 'perlakuan' atau 'tindakan' (Sudiarti 2018). Muamalah adalah hubungan antara sesama manusia untuk memenuhi keperluan jasmani dengan cara yang baik dan sesuai dengan ajaran agama Islam (Syaikhu 2020). Pengertian fiqh muamalah adalah hukum-hukum yang mengatur tindakan manusia dalam permasalahan 
dunia, seperti jual-beli, utang-piutang, sewa-menyewa, kerja sama, dan perikatan (Abdul Rahman Ghazaly 2012).

\section{Ruang Lingkup Muamalah;}

Muamalah Al-Adabiyah, yaitu muamalah yang membahas tentang aturan-aturan hukum syara' terkait aktivitas manusia dalam kegiatan bermasyarakat, dari segi subjeknya (Sa'adah Yuliana 2017) termasuk implementasi maqashid Syariah dalam konteks muamalah kontemporer (Galuh NKMR 2014), sedangkan Muamalah Al-Madiyah adalah muamalah yang membahas tentang aturan-aturan dari segi objek kebendaan, halal-haram, kejelasan benda tersebut untuk diperjual- belikan (syubhat). Salah satu bagian dari al-muamalah al-madiyah adalah akad sayembara (al-jualah) (Abdul Rahman Ghazaly 2012).

\section{Pengertian Akad dan Dasar Hukum Akad}

Menurut syariat, akad adalah salah satu cara untuk mendapatkan harta yang diridhai oleh Allah SWT dan wajib diterapkan dalam bermuamalah (Syaikhu 2020). Hukum melaksanakan akad telah diatur oleh Allah SWT dalam Al-Qur'an diantaranya terdapat dalam ayat-ayat berikut:

Dalam Q.S. Al-Maidah ayat 1, Allah SWT berfirman:

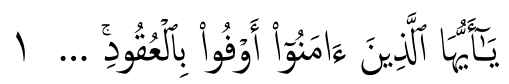

Artinya: "Wahai orang-orang yang beriman! Penuhilah janji-janji itu..."

Dan dalam Q.S. Al-Baqarah ayat 188, Allah SWT berfirman:

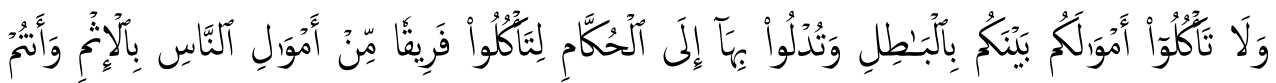

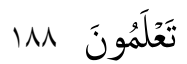

Artinya: "Dan janganlah kamu makan harta di antara kamu dengan jalan yang batil, dan (janganlah) kamu menyuap dengan harta itu kepada para hakim, dengan maksud agar kamu dapat memakan sebagian harta orang

\section{Prinsip-prinsip Akad} lain itu dengan jalan dosa, padahal kamu mengetahui."

Beberapa prinsip akad yang harus dipenuhi dalam pelaksanaannya yaitu (Hasan 2018): a) Ibadah; b) Kebebasan berkontrak; c) Bersifat mengikat; d) Amanah (jujur); e) Kesepakatan bersama; f) Adil dan keseimbangan kewajiban masing-masing pihak. 


\section{Pengertian Ju'alah}

Ju'alah berasal dari kata al-ju'lu berarti 'upah'secara istilah ju'alah adalah komitmen atau janji untuk memberikan hadiah atau imbalan tertentu atas terlaksananya suatu pekerjaan. Dalam istilah umum akad $J u$ 'alah sama dengan perlombaan (sayembara) yang dapat menguntungkan (Sudiarti 2018). Menurut KHES, ju'alah adalah perjanjian imbalan tertentu dari pihak pertama kepada pihak kedua atas terlaksananya tugas yang dikerjakan oleh pihak kedua demi kepentingan pihak pertama (Mardani 2013).

\section{Dasar Hukum Ju'alah}

Ju'alah adalah mubah, karena akad ju'alah diperlukan dalam kehidupan bermasyarakat. Sebagai makhluk sosial manusia tidak terlepas dari pertolongan sesama untuk memenuhi keperluan hidupnya (Sudiarti 2018).

Allah SWT berfirman dalam Q.S. Yusuf ayat 72 tentang hukum ju'alah:

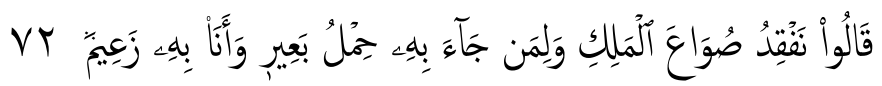

Artinya: “Mereka menjawab, "Kami kehilangan piala raja, dan siapa yang dapat mengembalikannya akan memperoleh (bahan makanan seberat) beban unta, dan aku jamin itu."

Imbalan dari akad ju'alah hanya boleh diterima apabila maj'ul lah (pihak yang melaksanakan akad) telah melaksanakan pekerjaan yang ditentukan oleh ja'il (pihak yang memberikan imbalan atas tercapainya pekerjaan) dan pihak ja'il harus memberikan imbalan yang telah dijanjikan kepada maj'ul lah atas terpenuhinya tugas yang telah ditawarkan (Harun 2017).

\section{Rukun dan Syarat Ju'alah}

Aqidain, yaitu dua orang yang melakukan akad yaitu ja'il (pihak yang memberikan imbalan dan yang menentukan pekerjaan yang dilaksanakan) dan maj'ul lah (pihak yang melaksanakan dan menerima imbalan).

Mahal al-'aqd atau objek Ju'alah, yaitu pekerjaan yang dilaksanakan harus berupa pekerjaan yang tidak dilarang oleh syara'.

Natijah, yaitu hasil pekerjaan harus jelas dan diketahui para pihak yang melakukan akad. Iwadh atau reward, yaitu imbalan atau upah yang sudah diketahui besar jumlahnya oleh ja'il dan diketahui para pihak pada waktu 
penawaran.Imbalan tidak boleh diberikan sebelum objek Ju'alah dilaksanakan (Sudiarti 2018).

\section{Akad Hibah}

Hibah berasal dari bahasa Arab al-hibah yang berarti menyalurkan, yaitu memberikan suatu secara sukarela tanpa ganti rugi atau timbal balik imbalan (Sudiarti 2018). Menurut jumhur ulama, hibah adalah akad yang berakibat pengalihan kepemilikan harta tanpa ganti rugi dalam keadaan hidup kepada orang lain secara sukarela (Abdul Rahman Ghazaly 2012). Jadi, hibah merupakan pemberian harta secara sukarela kepada orang lain tanpa mengharap imbalan dan orang yang diberi bebas menggunakannya.

\section{Dasar Hukum Hibah}

Dasar hukum hibah adalah sunah, karena hibah merupakan bentuk tolongmenolong yang dianjurkan oleh Allah SWT (Abdul Rahman Ghazaly 2012), berdasarkan pada firman Allah SWT dalam Q.S. Al-Baqarah ayat 177:

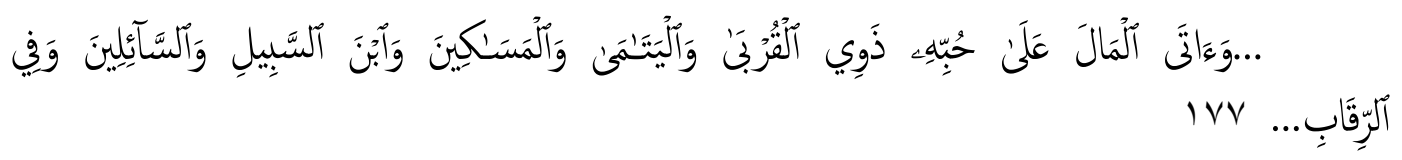

Artinya: “...memberikan harta yang dicintainya kepada kerabatnya, anakanak yatim, orang-orang miskin, musafir (yang memerlukan pertolongan), dan orang-orang yang meminta-minta, dan memerdekakan hamba sahaya..."

\section{Perbedaan antara Ju'alah, Ijarah dan Hibah}

Perbedaan antara ju'alah dengan hibah adalah dalam hibah seseorang memberikan sesuatu pada pihak lain secara sukarela tanpa harus melakukan atau mengerjakan pekerjaan yang ditentukan, sedangkan pada akad ju'alah pihak yang akan diberi imbalan atau reward harus melaksanakan tugas yang telah ditentukan terlebih dahulu oleh pihak yang memberi imbalan sebelum ia menerima imbalan. Sedangkan perbedaan antara Ju'alah dengan Ijarah (sewa-menyewa) adalah Ju'alah tetap sah dilaksanakan dengan orang yang belum jelas; pekerjaan yang belum pasti; tidak diharuskan adanya ijab dan kabul karena $J u$ 'alah dilakukan atas keinginan pribadi; akad Ju'alah bersifat tidak mengikat; dan imbalan tidak dapat diterima sebelum tugas yang diberikan telah selesai dilaksanakan, sedangkan Ijarah kedua belah pihak yang melakukan akad harus saling mengenal; akad tidak 
sah apabila pekerjaannya tidak jelas; harus ada ijab dan qabul; tidak dapat dibatalkan secara sepihak; dan upah dapat diberikan sebelum atau sesudah pekerjaan telah dilaksanakan (Haryono 2017).

\section{Aplikasi Snack Video}

Aplikasi adalah salah satu unit software atau perangkat lunak yang dirancang untuk melakukan tugas tertentu dan melayani keperluan seperti pelayanan masyarakat, perniagaan, iklan, hiburan/game, dan lain-lain (Sari 2017). Aplikasi dikategorikan ke dalam 3 jenis, (Prawiro 2021): 1) Aplikasi Desktop, yaitu aplikasi yang dijalankan hanya dengan perangkat laptop, komputer, dan $P C$. 2) Aplikasi Web, yaitu aplikasi yang dijalankan menggunakan koneksi internet melalui perangkat komputer. 3) Aplikasi Mobile, yaitu aplikasi yang dijalankan pada perangkat telepon pintar yang sekarang sudah banyak digunakan karena lebih mudah dan praktis, seperti aplikasi komunikasi, aplikasi tools, dan aplikasi hiburan.

Aplikasi Snack Video merupakan aplikasi milik perusahaan bernama Kuaishou Technology asal Beijing, China yang didukung oleh perusahaan Tencent Holding sebagai investor. Aplikasi Snack Video termasuk dalam kategori aplikasi mobile dengan jenis aplikasi hiburan, pertama kali diluncurkan pada tanggal 7 Agustus 2019 dan baru masuk pasar Indonesia sejak tahun 2020 (Atmoko 2021).

\section{Profil Aplikasi Snack Video}

Snack Video adalah aplikasi hiburan yang menampilkan video-video berdurasi singkat yang terdiri dari berbagai macam kategori pilihan mulai dari hiburan, berita, fashion, kumpulan tips, dan beberapa pilihan video lainnya (Store 2021). Aplikasi Snack Video mulai banyak diminati saat mereka mengadakan event berupa misi untuk para penggunanya pada awal tahun 2021 (Melisa 2021).

Ada tiga macam misi yang diselenggarakan oleh aplikasi Snack Video untuk para penggunanya yang dapat menghasilkan uang, yaitu:

Pertama, misi menonton video. Pengguna yang berhasil menyelesaikan misi menonton video ada pada aplikasi Snack Video akan diberikan imbalan berupa koin dengan kisaran 50-150 koin per video yang berhasil ditonton sampai selesai. Semakin banyak video yang berhasil ditonton maka koin yang didapat 
akan semakin banyak (Fatimah 2021). Snack Video berdurasi singkat, 5-10 detik per video (Rahmad 2021).

Kedua, misi check-in. Misi check-in adalah misi yang dilakukan dengan cara masuk pada aplikasi Snack Video setiap hari selama 30 hari secara berturutturut. Saat melakukan misi check-in pengguna akan diberikan koin sesuai dengan jumlah yang telah mereka tampilkan, seperti pada gambar berikut (Safitri, Pengguna Aplikasi Snack Video 2021):

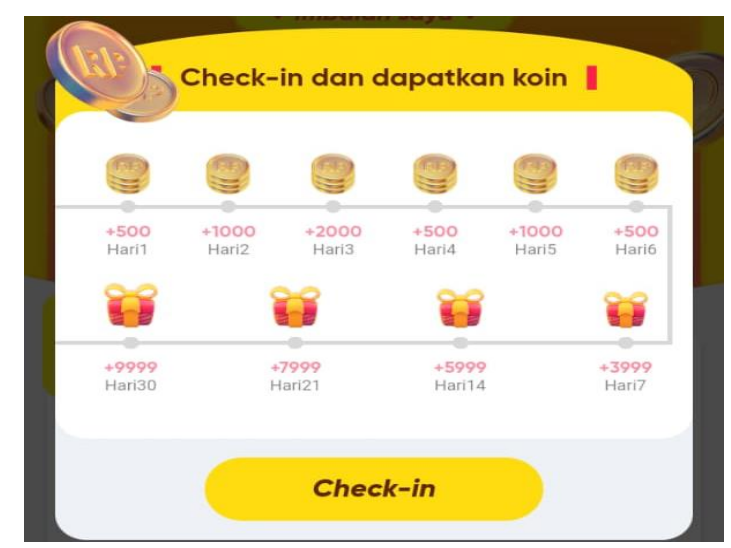

Gambar 1. misi check-in dalam aplikasi Snack Video Sumber: Screen shot pada aplikasi Snack Video, 27 Mei 2021

Ketiga, misi mengundang teman. Misi ini dilakukan dengan membagikan kode undangan yang disediakan aplikasi Snack Video kepada calon pengguna yang belum pernah mengunduh dan menggunakan aplikasi Snack Video agar orang tersebut ikut menggunakan aplikasi tersebut, jika berhasil maka diberikan imbalan berupa uang senilai Rp.52.000 per orang yang berhasil diundang (Safitri, Pengguna Aplikasi Snack Video 2021).

\section{Cara Mengunduh, Menggunakan dan Menukarkan Imbalan pada Aplikasi}

\section{Snack Video Agar Mendapat Uang}

Untuk bisa menggunakan dan mendapatkan penghasilan dari aplikasi Snack Video dapat dilakukan langkah-langkah berikut:

Pertama; Buka aplikasi Google Play Store, kedua; ketik 'Snack Video' kemudian klik telusuri, ketiga; Setelah muncul aplikasi Snack Video, lalu klik 


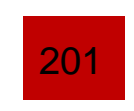

'instal', keempat; Setelah proses instal selesai pengguna dapat langsung masuk pada aplikasi Snack Video.

Setelah pengguna berhasil mengunduh aplikasi Snack Video, pengguna diminta melakukan pendaftaran dengan memasukkan nama pengguna dan nomor HP/e-mail, setelah data yang dimasukkan telah diterima, pengguna diminta untuk memilih jenis video kesukaan pengguna, jika tidak ingin memilih pengguna bisa melakukan klik 'skip' untuk melanjutkan langkah pendaftaran berikutnya, langkah terakhir pengguna akan diminta untuk memilih jenis kelamin dan hari ulang tahun setelah itu pengguna telah terdaftar sebagai pengguna baru aplikasi Snack Video.

Agar mendapatkan penghasilan dari misi menonton video pengguna harus melakukan tahapan berikut: 1) Membuka aplikasi Snack Video, 2) Pilih video yang ingin ditonton, 3) Menonton video sampai selesai, 4) Setelah video selesai ditonton pengguna langsung mendapat koin sebagai imbalan terlaksananya misi menonton video (Melisa 2021).

Selain itu, pengguna bisa menambah koin dengan misi check-in, melalui langkah-langkah berikut: 1) Buka aplikasi Snack Video, 2) Klik icon koin, lalu check-in, 3) Klik check-in dan pengguna akan mendapat koin sesuai dengan hari ke berapa ketika pengguna melakukan check-in, 4) Lakukan check-in setiap hari tanpa terlewat agar koin yang didapat akan terus meningkat hingga hari ke-30.

Misi terakhir agar pengguna bisa mendapat tambahan penghasilan adalah mengundang teman untuk menggunakan aplikasi Snack Video. Melalui langkahlangkah berikut: 1) Buka aplikasi Snack Video, 2)Klik icon koin, lalu undang teman dan check-in, 3) Klik 'undang' pada bagian 'undang teman baru dan dapatkan uang', 4) Klik salin kode undangan dan bagikan kode undangan.

Untuk menukarkan imbalan koin yang telah terkumpul pihak Snack Video akan memberikan beberapa pilihan penukaran imbalan, koin-koin yang telah terkumpul dikonversi terlebih dahulu menjadi nominal uang rupiah. 50 koin setara dengan Rp.1 dan dapat dicairkan melalui aplikasi e-money seperti OVO, Dana, dan GoPay atau pengguna juga bisa menukarnya langsung menjadi pulsa dan kuota internet. Pengguna dapat menarik uang sebanyak Rp.50.000 saja per harinya, jika menginginkan lebih, bisa ditarik di hari berikutnya (Fatimah 2021). 
Berikut langkah-langkah yang dilakukan agar uang imbalan dapat ditarik menggunakan aplikasi e-money (Admin, Cara Menarik Uang dari Snack Video Lewat Ovo, Dana, Gopay Begini Caranya!, 2021): 1)Buka aplikasi Snack Video, 2) Klik icon 'rupiah penghasilan', 3) Klik menarik, 4) Pilih nominal cash yang ingin ditarik, lalu klik 'tarik', 5) Muncul verifikasi nomor HP pengguna, dan masukkan kode rahasia dari aplikasi Snack Video, 6) Langkah selanjutnya pilih metode pembayaran digital melalui (OVO, Dana dan GoPay), 7) Masukkan nama bank digital yang pengguna pakai beserta nomor tujuannya, 8) Klik 'kas keluar', 9) Proses penarikan selesai dan pengguna bisa menunggu 1 hari kerja untuk melakukan pencairan.

Apabila pengguna tidak mempunyai aplikasi e-money, pengguna dapat menukarkan imbalan yang didapat menjadi pulsa, token listik maupun kuota internet. Untuk melakukan penukaran voucher yang telah didapat, pastikan bahwa pengguna memiliki akun Shopee untuk melakukan penukaran voucher menjadi pulsa atau kuota internet.

\section{Analisis Akad dan Asas-Asas Muamalah pada Aplikasi Snack Video}

Dalam Islam melaksanakan akad muamalah hukumnya adalah mubah selama rukun dan syaratnya tidak bertentangan dengan syariat Islam. Pada aplikasi Snack Video pengguna diarahkan untuk menyelesaikan misi-misi agar pengguna bisa menerima imbalan berupa koin yang dapat ditukarkan menjadi uang, dalam hal ini penghasilan yang didapat dari misi-misi pada aplikasi Snack Video dapat dianalogikan dengan akad ju'alah yang mana misi-misi merupakan objek akad yang harus diselesaikan dan koin yang didapat setelah menyelesaikan misi merupakan imbalan atau iwadh.

Ditinjau dari rukun dan syarat ju'alah, maka penghasilan yang didapat dari aplikasi Snack Video adalah pada Aqidain, pihak Snack Video sebagai ja'il (pemberi imbalan dan penentu pekerjaan yang dilaksanakan) dan pengguna aplikasi Snack Video sebagai maj'ul lah (penerima imbalan dari hasil menyelesaikan pekerjaan). Sedangkan pada Mahal al-'aqd atau objek ju'alah, dalam aplikasi Snack Video pekerjaan yang dimaksud adalah misi-misi yang 
diarahkan oleh pihak Snack Video yaitu berupa misi menonton video, misi checkin dan misi mengundang teman.

Faktanya, pengguna pernah menjumpai video yang menampilkan wanita berjoget dengan pakaian minim, misi ini bertentangan dengan syarat dari rukun akad ju'alah karena dalam akad ju'alah, mahal al-'aqd harus pekerjaan yang tidak dilarang oleh syara'. Menonton video yang berisi konten yang memperlihatkan aurat tidak dibolehkan dalam Islam karena aurat merupakan hal yang tidak boleh diperlihatkan pada semua orang, sebagaimana firman Allah SWT dalam Q.S. An-Nur ayat 31:

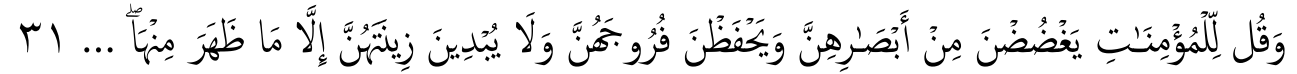

Artinya: "Dan katakanlah kepada para perempuan yang beriman, agar mereka menjaga pandangannya, dan memelihara kemaluannya, dan janganlah menampakkan perhiasannya (auratnya) kecuali yang (biasa) terlihat..."

Melalui firman Allah SWT tersebut menonton video yang memperlihatkan aurat saja tidak diperbolehkan, apalagi uang yang diperoleh dari misi menonton tersebut tidak dibolehkan, karena saat menonton video tersebut lebih banyak mendatangkan mudharat dibanding dengan manfaat dengan mempertimbangkan natijah, yaitu hasil pekerjaan harus manfaat.

Pada aplikasi Snack Video, reward yang diberikan kepada pengguna saat menyelesaikan misi menonton video tidak diketahui berapa jumlahnya karena pada setiap selesai menonton video koin yang didapat berbeda-beda yaitu kisaran 40-150 koin per video yang selesai ditonton. Tidak seperti misi check-in dan misi mengundang teman, pihak Snack Video sudah memberi tahu berapa banyak koin yang didapat setelah berhasil menyelesaikan misi tersebut. untuk misi check-in pengguna akan mendapat koin sesuai dengan hari keberapa pengguna melakukan check-in dan saat berhasil mengundang teman pengguna akan diberikan uang sebesar Rp.52.000 per orang. Pada transaksi Ju'alah, imbalan tidak boleh diberikan sebelum objek ju'alah dilaksanakan.

Selain menjalankan misi-misi untuk mendapatkan penghasilan, pengguna juga dapat memberikan apresiasi kepada pembuat video konten pada saat mereka melakukan siaran langsung, pemberian apresiasi ini dapat dikategorikan sebagai 
akad hibah dimana pengguna memberikan apresiasi secara sukarela agar pembuat video konten merasa dihargai. Rukun dan syarat hibah dalam aplikasi Snack Video ini sesuai syari'ah, yaitu wahib (pemberi), pengguna memberikan apresiasi dalam bentuk stiker yang dapat ditukarkan menjadi uang oleh pembuat konten video.

Mauhub lah (penerima), adalah pembuat video konten. Terakhir mauhub (barang atau harta yang dihibahkan), syaratnya, benda atau harta yang dihibahkan nyata dan memiliki nilai atau manfaat, dapat dimiliki dan dapat dipindah kepemilikannya, bukan benda yang dzatnya dilarang oleh syara'.

Dalam aplikasi Snack Video barang yang diberikan pengguna kepada pembuat video konten adalah stiker yang dapat ditukar menjadi uang. Sebelumnya pengguna yang menonton video akan membeli diamond pada aplikasi Snack Video sebagai alat tukar dari stiker yang diberikan kepada pembuat video konten.

Shighat (ijab dan qabul), yaitu sesuatu yang dilafalkan saat penyerahan hibah baik dengan lisan maupun tulisan. Dengan adanya shighat, maka akad akan jelas sebagai pijakan dalam pelaksanaannya.

Beberapa manfaat dari akad hibah yaitu, pertama, tercipta keharmonisan dan rasa akrab antara sesama, pemberi dan penerima bisa saling mengenal dan tercipta pertemanan baru diantara keduanya. Kedua, hibah dianjurkan agar terbentuk kerjasama, saling memberi dan membantu kesulitan saudaranya. Pemberian apresiasi memicu semangat pembuat video konten untuk mengunggah video-video baru (Sudiarti 2018).

Asas-asas muamalah pada aplikasi Snack Video adalah Asas Ibahah, yang memberikan kebebasan dalam menciptakan akad baru selama tidak bertentangan dengan hukum Islam yang berlaku kaidah "al-ash fil mu'amalah al-ibahah selama tidak ada dalil yang melarang". Dalam aplikasi Snack Video yang penulis bahas, kegiatan misi check-in dan misi mengundang teman tidak bertentangan dengan hukum Islam karena tidak ada hal yang melanggar dari aturan Islam. Saat melakukan misi check-in pengguna hanya diarahkan untuk rutin masuk pada aplikasi Snack Video dan melakukan absen harian setiap hari agar pengguna bisa mengumpulkan koin. Untuk misi mengundang teman pengguna hanya membagikan kode undangan pada akun sosial media pengguna lainnya agar 
keluarga dan teman yang belum mengunduh dan menggunakan aplikasi Snack Video bisa mengikuti untuk menggunakan aplikasi tersebut. Sedangkan untuk misi menonton video, jika terdapat video yang bertentangan dengan hukum Islam dan dapat mengundang fitnah, maka misi menonton pada aplikasi Snack Video tidak bisa dijadikan kegiatan penghasil uang sesuai dengan ketentuan hukum Islam.

Asas kebebasan untuk melakukan suatu akad selama tidak mengganggu orang lain dan masih dalam batas-batas hukum Islam. Dalam hal ini pihak Snack Video tidak membebani penggunanya untuk melakukan misimisi dengan persyaratan yang membuat pengguna merasa terpaksa melakukannya, apabila pengguna ingin mendapat imbalan maka pengguna hanya perlu mengikuti setiap misi yang telah disediakan pihak Snack Video apabila pengguna tidak berminat untuk mengikuti misi-misi yang diarahkan pihak Snack Video juga tidak memaksa pengguna.

Asas konsensualisme, pada aplikasi Snack Video sebelum pengguna dapat menggunakan aplikasi tersebut, pihak Snack Video akan meminta beberapa persyaratan sebagai tanda bergabungnya pengguna dalam aplikasi Snack Video, pengguna yang bersedia mengikuti dan menyetujui persyaratan yang diberikan selanjutnya bisa mengikuti dan melaksanakan misi-misi yang diarahkan untuk bisa mendapat imbalan dari pihak Snack Video.

Asas keseimbangan, pada aplikasi Snack Video pengguna yang mengikuti misi-misi yang diarahkan dengan benar akan diberikan imbalan sesuai dengan banyak atau sedikit misi yang pengguna selesaikan.

Asas kemashlahatan, setiap misi yang diselenggarakan memberikan keuntungan pada kedua pihak. Pengguna menggunakan dan menonton videovideo pada aplikasi Snack Video selain bisa mendapatkan hiburan dan informasiinformasi terbaru pengguna juga bisa mendapat keuntungan finansial.

Asas Amanah, yaitu setiap pihak yang berakad tidak diperkenankan melakukan pemerasan pada mitranya. Selama pengguna menggunakan aplikasi Snack Video pengguna tidak pernah diminta untuk melakukan pembayaran dalam menonton video pada aplikasi tersebut, untuk masuk dan menggunakan aplikasi Snack Video pengguna hanya memerlukan kuota internet. (Fatimah 2021). 
Dalam memberikan imbalan atas terlaksananya misi-misi pihak Snack Video juga selalu memberikan dan menukarkan imbalan tepat pada waktu yang sama setiap harinya agar pengguna bisa mengambil imbalan sesuai dengan pilihan pengguna baik ditukar menjadi voucher pulsa dan kuota internet atau dicairkan melalui e-money (OVO, Dana dan GoPay).

Asas keadilan, pada aplikasi Snack Video juga memberikan imbalan bagi para pembuat video di aplikasinya. Selain itu pihak Snack Video juga memberikan kesempatan bagi pengguna yang menonton video untuk memberikan apresiasi kepada para pembuat video saat mereka melakukan video siaran langsung dengan cara memberikan like berupa stiker berbayar, stiker tersebut dapat dibeli dengan diamond yang disediakan oleh pihak Snack Video. Sebelumnya pengguna membeli diamond terlebih dahulu dari pihak Snack Video agar nanti dapat ditukarkan dengan stiker ketika ingin melakukan apresiasi kepada pembuat video saat melakukan video siaran langsung. Walaupun bukan sebuah keharusan pihak Snack Video telah memberi kesempatan bagi pengguna yang menonton video untuk secara suka rela memberikan apresiasi kepada pembuat konten agar mereka rajin mengirim video-video baru.

Asas 'adamul gharar, yaitu setiap bentuk muamalah tidak dibenarkan terdapat unsur penipuan yang dapat merugikan salah satu pihak. Aplikasi Snack Video telah mendapat izin untuk menjalankan usahanya oleh SWI (Satgas Waspada Investasi) pada tanggal 23 Maret 2021 karena telah memenuhi persyaratan dan perizinan dan pengguna aplikasi Snack Video tidak pernah mengalami penipuan selama menggunakan dan menjalankan misi, imbalan yang pengguna dapatkan dari hasil menjalankan misi juga selalu diberikan oleh pihak Snack Video.

Dalam perpektif muamalah kontemporer, penggunaan aplikasi Snack Video untuk menghasilkan uang diperbolehkan selama tidak terdapat unsur haram dalam setiap video yang ditonton. Ketika dalam menjalankan aktivitas menonton video terdapat banyak tayangan yang melanggar hukum Islam dibandingkan yang tidak, maka uang atau pendapatan yang dihasilkan dari aktivitas menonton pada aplikasi Snack Video menjadi makruh bahkan dapat menjadi haram karena telah tercampur dengan aktivitas yang dapat 
merusak maqashid syariah pada unsur daruriyyat, yaitu hifdz al-mal yaitu melindungi harta dari unsur-unsur yang batil (Muzlifah 2013).

\section{KESIMPULAN}

Pendapatan finansial dari aplikasi Snack Video diperoleh dengan mendaftar pada aplikasi Snack Video setelah mengunduh di Google Play Store dan memenuhi semua persyaratan. Setelah itu pengguna diarahkan untuk menjalankan misi-misi seperti misi menonton video, check-in, dan mengundang teman. Jika berhasil, maka pengguna mendapatkan imbalan berupa koin yang dapat ditukar menjadi uang. Uang yang telah terkumpul dapat dicairkan melalui aplikasi e-money (OVO, Dana dan GoPay), voucher pulsa atau kuota internet melalui aplikasi Shopee.

Aplikasi Snack Video tak ubahnya sayembara, dalam fiqh muamalah disebut dengan akad ju'alah. Selama misi pada Snack Video tidak bertentangan dengan hukum Islam dan tidak membawa kemudharatan, maka akad ju'alah yang dilaksanakan pada aplikasi tersebut sah. Membeli produk pada aplikasi Snack Video dalam fiqh muamalah tergolong sebagai hibah.

Dalam konsep muamalah kontemporer, pendapatan yang dihasilkan dari kegiatan menonton pada aplikasi Snack Video menjadi makruh bahkan dapat menjadi haram jika terdapat aktivitas yang dapat merusak maqashid syariah pada unsur daruriyyat, yaitu hifdz al-mal, menjaga harta dari hal-hal batil. Pentingnya mengetahui misi-misi yang dilakukan oleh para pengguna aplikasi Snack Video agar uang yang pengguna dapatkan dari misi-misi tersebut mendapat berkah dan keridhaan dari Allah SWT. 


\section{DAFTAR PUSTAKA}

Abdul Rahman Ghazaly, dkk. 2012. Fiqh Muamalat . Jakarta: Kencana.

Admin. 2021. "Cara Menarik Uang dari Snack Video Lewat Ovo, Dana, Gopay Begini Caranya!, ." Website GarutSelatan.Info, https://www.garutselatan.info/2021/02/cara-menarik-uang-dari-snack-

video.html . Diakses Juni 27, 2021.

https://www.garutselatan.info/2021/02/cara-menarik-uang-dari-snackvideo.html.

-. 2021. "Cara Menukar Koin Snack Video ke Pulsa." Website tomtekno.com, https://www.tomtekno.com/2021/04/cara-menukarkan-koin-di-snack-

video.html. Diakses Juni 27, 2021. https://www.tomtekno.com/2021/04/cara-menukarkan-koin-di-snackvideo.html.

—. 2021. "Cara Menukar Koin Snack Video ke Pulsa."Website tomtekno.com, https://www.tomtekno.com/2021/04/cara-menukarkan-koin-di-snack-

video.html. Diakses JUni 27, 2021. https://www.tomtekno.com/2021/04/cara-menukarkan-koin-di-snackvideo.html.

- 2021. GarutSelatan.Info, https://www.garutselatan.info/2021/03/kabarterbaru-swi-nyatakan-snack-video-legal.htm. Maret. Diakses Maret 31, 2021. https://www.garutselatan.info/2021/03/kabar-terbaru-swi-nyatakansnack-video-legal.htm, .

Atmoko, Bambang Dwi. 2021. Website Gizmologi.id https://gizmologi.id/aplikasi/mengenal-snack-video/. Diakses Mei 31, 2021. https://gizmologi.id/aplikasi/mengenal-snack-video/.

Barlian, Eri. 2016. Metode Penelitian Kualitatif \& Kuantitatif. . Padang: Suka Bina Press.

Dewi, Retia Kartika. t.thn. Website Kompas, https://www.kompas.com/tren/read/2021/03/02/192700565/ini-alasan-ojkblokir-dan-tetapkan-snack-video-sebagai-aplikasi-ilegal . Diakses Maret 15, 2021. https://www.kompas.com.

Fatimah, Melisa dan, wawancara oleh Raudatunnisa. 2021. Pengguna Aplikasi Snack Video (22 April ).

Galuh NKMR, Hasni Noor. 2014. "Konsep Maqashid Al-Syariah Dalam Menentukan Hukum Islam (Perspektif Al-Syatibi dan Jasser Auda).” Al Iqtishadiyah, Jurnal Ekonomi Syariah dan Hukum Ekonomi Syariah. 5069.

Gautama, Wakos Reza. 2021. Suara Lampung, https://lampung.suara.com/read/2021/03/04/091000/snack-video-diblokirini-fakta-seputar-snack-video-yang-belum-anda-tahu?page=2. 4 Maret. Diakses Maret 23, 2021. https://lampung.suara.com.

H, Darmawati. 2018. “Akad Dalam Transaksi Ekonomi Syari'ah, Jurnal Sulasena, 12 (2) 2018, hlm. 158-159.” Jurnal Sulasena 12 (2).

Hardani, dkk. 2020. Metode Penelitian Kualitatif \& Kuantitatif. . Yogyakarta: Pustaka Ilmu. 
Harizan. 2017. "Upaya Preventif Berkembangnya Money Game di Indonesia." Jurnal Ilmu Syariah dan Perbankan Islam, 2 (1) 81.

Harun. 2017. Fiqh Muamalah. Surakarta: Muhamadiyah University Press.

Haryono. 2017. "Konsep Al-Ju'alah dan Model Aplikasinya dalam Kehidupan Sehari-hari. .” Jurnal Hukum Islam dan Pranata Sosial Islam GF, 5 (09).

Hasan, Akhmad Farroh. 2018. Fiqh Muammalah dari Klasik Hingga Kontemporer (Teori dan Praktek). Malang: UIN-Maliki Press.

Indonesia, Kementerian Pendidikan dan Kebudayaan Republik. 2021. Kementerian Pendidikan dan Kebudayaan Republik Indonesia, KBBI Daring, Website Kemdikbud, https://kbbi.kemdikbud.go.id/entri/Video. Diakses Maret 18, 2021. https://kbbi.kemdikbud.go.id/entri/Video.

Indoprogramer. 2021. Website Idprogrammer, https://idprogrammer.com/fungsidan-jenis-aplikasi-android. Diakses April 26, 2021. https://idprogrammer.com/fungsi-dan-jenis-aplikasi-android.

Ismail Suardi Wekke, dkk. 2019. Metode Penelitian Ekonomi Syariah. . Yogyakarta: Gawe Buku.

Kementerian Pendidikan dan Kebudayaan Republik Indonesia, KBBI Daring. 2021. Kemdikbud, https://kbbi.kemdikbud.go.id/entri/Hukum . Diakses Maret 18, 2021. https://kbbi.kemdikbud.go.id/entri/Hukum .

Luthfiyah, Muh. Fitrah \&. 2017. Metodologi Penelitian; Penelitian Kualitatif, Tindakan Kelas \& Studi Kasus. . Jawa Barat: CV Jejak.

Mardani. 2013. Fiqh Ekonomi Syariah (Fiqh Muamalah). Jakarta: Kencana.

MariBelajar. 2021. Website MateriBelajar, https://materibelajar.co.id/pengertianvideo/. Diakses April 27, 2021. https://materibelajar.co.id/pengertianvideo/.

Marzuki. 2017. Pengantar Studi Hukum Islam . Yogyakarta: Penerbit Ombak.

Melisa, wawancara oleh Raudatunnisa. 2021. Pengguna Aplikasi Snack Video (15 April).

MUI. 2017. "Fatwa DSN No.62/DSN-MUI/XII/2007." Fatwa DSN No.62/DSNMUI/XII/2007. Jakarta: Kemenag RI, Desember.

Muzlifah, Eva. 2013. "Maqashid Syariah Sebagai Paradigma Dasar Ekonomi Islam." Jurnal Ekonomi dan Hukum Islam 78-83.

Novika, Soraya. 2021. detikcom, https://finance.detik.com/berita-ekonomibisnis/d-5374792/nonton-video-bisa-dapat-duit-aman-nggak-ya,. Diakses Maret15 2021. https:/finance.detik.com/berita-ekonomi-bisnis/d5374792/nonton-video-bisa-dapat-duit-aman-nggak-ya.

-. 2021. Nonton Video Bisa Dapat Duit, Aman Nggak Ya? 15 Maret. https://finance.detik.com/berita-ekonomi-bisnis/d-5374792/nonton-videobisa-dapat-duit-aman-nggak-ya.

Nurcahyono, Fendi. 2012. "Pembangunan Aplikasi Penjualan dan Stok Barang Pada Toko Nuansa Elektronik Pacita." Jurnal Speed Sentra Penelitian Engineering dan Edukasi, 4 (3) 12.

Nurhayati, Yati. 2020. Pengantar Ilmu Hukum. . Bandung: Nusa Media.

Prawiro, M. 2021. Pengertian Aplikasi: Arti, Fungsi, Klasifikasi, dan Contoh Aplikasi, Website maxmanroe, https://www.maxmanroe.com/vid/teknologi/pengertian-aplikasi.html. 
Diakses

April

26 ,

2021.

https://www.maxmanroe.com/vid/teknologi/pengertian-aplikasi.html.

Rahmad, Fatimah dan Alfian, wawancara oleh Raudatunnisa. 2021. Pengguna Aplikasi Snack Video (22 April).

Rizki. 2021. Website Crytowi, https://www.crytowi.com/pengertian-video/. Diakses Maret 18, 2021. https://www.crytowi.com/pengertian-video/.

Rohidin. 2016. Pengantar Hukum Islam. Yogyakarta: Lintang Rasi Aksara Boos.

Sa'adah Yuliana, dkk. 2017. Transaksi Ekonomi dan Bisnis dalam Tinjauan Fiqh Muamalah. Yogyakarta: Idea Press .

Safitri, Rika, wawancara oleh Raudatunnisa. 2021. Pengguna Aplikasi Snack Video (15 April).

Safitri, Rika, wawancara oleh Raudatunnisa. 2021. Pengguna Aplikasi Snack Video (27 Mei).

Sari, Yuntari Purba. 2017. "Rancang Bangun Aplikasi Penjualan dan Persediaan Obat Pada Apotek Merben.” Jurnal Sistem Informasi dan Komputerisasi Akuntansi, 1 (1) .

Store, Google Play. 2021. Website Google Store.com, https://play.google.com/store/apps/details?id=com.kwai.bulldog. Diakses Mei 31, 2021. https://play.google.com/store/apps/details?id=com.kwai.bulldog.

Sudiarti, Sri. 2018. Fiqh Muamalah Kontemporer. Medan: FEBI UIN-SU Press.

Sugiono. 2019. Metode Penelitian Kuantitatif Kualitatif dan R\&D. . Bandung: Alfabeta.

Suryaningsih. 2018. Pengantar Ilmu Hukum . Samarinda: Mulawarman University Press.

Syaikhu, dkk. 2020. Fikih Muamalah: Memahami Konsep dan Dialektika Kontemporer. Yogyakarta: Penerbit K-Media. 